\title{
Супер-разрешение без микросканирования: восстановление субпиксельных изображений из фотосигналов окрестных диодов матрицы как некорректно поставленная задача
}

\author{
В.А. Стучинский, А.В. Вишняков \\ Институт физики полупроводников им. А.В. Ржанова, Новосибирск, \\ 630090, пр. Академика Лаврентьева, 13 \\ тел:+7 (383) 330-4968, факс:+7 (383) 333-2771, эл.nочта: stuchin@isp.nsc.ru
}

DOI 10.34077/RCSP2021-144

Решение задачи построения эффективных алгоритмов восстановления субпиксельных изображений (СИ) из измеренной (без применения систем микросканирования) совокупности сигналов матричных ФПУ имело бы большое практическое значение. Действительно, хотя в настоящее время микросканирование и используется для решения ряда задач оптического детектирования (улучшение разрешения ФПУ, устранение геометрического шума фотоприемников, детектирование движущихся объектов, и др.), - использование микромеханических устройств значительно усложняет конструкцию проектируемых систем.

В настоящей работе изучался следующий алгоритм восстановления СИ в фотоприемных матрицах, базирующийся на использовании в них фотоэлектрической связи между фотоэлементами. Полагаем, что подлежащее регистрации изображение сосредоточено в области между четырьмя диодами матрицы. Мы разбиваем эту область на 4x4 квадратных площадок, - и, моделируя диффузию фотогенерированных носителей заряда (ФНЗ) в матрице методом Монте-Карло [1], вычисляем фотосигналы $4 \mathrm{x} 4$ окрестных диодов при однородном освещении светом каждой из площадок. При освещении фрагмента матрицы, образованной 16-ю площадками, “фигурным” излучением (например, в виде однородно засвеченного круга, кольца, и т.п.), применяя тот же метод моделирования, мы аналогичным образом можем сосчитать фотосигналы рассматриваемых 16-ти фотодиодов. Теперь задача состоит в том, чтобы приблизить использованное для засветки матрицы “фигурное” изображение картиной, образованной однородно (но с разной интенсивностью!) засвеченными площадками.

Математически задача состоит в решении системы линейных уравнений с матрицей $16 \times 16$ элементов, представляющих собой сигналы фотодиодов при засветке светом отдельных виртуальных ФЧЭ. В наших расчетах было показано, что рассматриваемая задача проявляет свойства некорректнопоставленной задачи (сильную зависимость решения от погрешности исходных данных), что, повидимому, является следствием близости друг к другу коэффициентов линейной системы (см., например, [2]). Нами были изучены характерные искажения вычисленных СИ по сравнению с засветочными изображениями. Выяснилось, что алгоритм плохо “чувствует" наличие в засвеченных областях темных включений (например, плохо различает между засвеченными кругом и кольцом); в случае добавления к сигналу одного из фотодиодов малой добавки “норовит” чересчур сильно выдвинуть в сторону этого фотодиода сильно засвеченный виртуальный пиксель с образованием внутренней темной области; и т.д. Показано, что разрешимость задачи улучшается после наложения на её решение некоторых специальных требований. Например, если ограничиться рассмотрением задач астронавигации, в которых искомое изображение представляет собой малое сплошное пятно (засвечен один виртуальный пиксель "расширенной” матрицы или малое число таких пикселей), то положение пятна может быть оценено уже из рассмотрения фотосигналов четверки ближайших к пятну фотодиодов. Если для каждой пары фотодиодов отношение их фотосигналов дается числом $\eta_{i, j}$, то такое число задает на плоскости фотоприемной матрицы линию, вдоль которой соотношение фотосигналов двух диодов будет постоянным, равным этому числу. Выбирая из четверки диодов всевозможные их пары, по положению точек пересечений соответствующих линий мы можем определить область нахождения виртуальных пикселей с ненулевой интенсивностью засветки, которые только и нужно включать в задачу для “расширенной” матрицы. Тем самым можно уменьшить ранг матрицы линейной системы задачи и, вообще говоря, улучшить её (задачи) разрешимость.

\section{Лumepamypa}

[1] В.А. Стучинский, А.В. Вишняков, Труды XXV Межд. научно-технической конференции и школы по фотоэлектронике и приборам ночного видения в 2-х томах. Том 2. М.: АО «НПО «Орион», 2018 г. - М.: Издательство «ОФСЕТ МОСКВА», 2018, с. 430-433.

[2] Ю.П. Петров, В.С. Сизиков, Корректные, некорректные, и промежуточные задачи с приложениями. Учебное пособие для вузов. Санкт-Петербург: Политехника, 2003. 261 c. 